\title{
Stage III Hepatocellular Carcinoma AJCC v6
}

National Cancer Institute

\section{Source}

National Cancer Institute. Stage III Hepatocellular Carcinoma A/CC v6. NCI Thesaurus. Code $\mathrm{C5760.}$

Stage III includes: IIIA: (T3, N0, M0); IIIB: (T4, N0, M0); IIIC: (Any T, Any N, M0). IIIA: T3: Multiple tumors more than $5 \mathrm{~cm}$ or tumor involving a major branch of the portal or hepatic vein(s). T4: Tumors(s) with direct invasion of adjacent organs other than the gallbladder or with perforation of visceral peritoneum. N0: No regional lymph node metastasis. N1: Regional lymph node metastasis. M0: No distant metastasis. (AJCC 6th ed.) - 2003 